\title{
Pseudo-Bartter Syndrome and Intermediate Sweat Chloride Levels-It Could Still be Cystic Fibrosis!
}

\author{
Madhan Kumar $^{1} \cdot$ Sneha Deena Varkki ${ }^{1}$ \\ Received: 1 February 2021 / Accepted: 8 March 2021 / Published online: 7 April 2021 \\ (C) Dr. K C Chaudhuri Foundation 2021
}

To the Editor: Cystic Fibrosis (CF) is a rare genetic condition with predominant respiratory and gastrointestinal manifestations. Characteristic electrolyte abnormalities of hypokalemia, hypochloremia, and metabolic alkalosis referred to as Pseudo-Bartter syndrome (PBS) is common in CF infants living in tropical countries [1]. Inadequate cystic fibrosis transmembrane conductance regulator (CFTR) protein on cell surface of sweat ducts leads to increased excretion of chloride and sodium in the sweat. This is the pathophysiological basis for elevated sweat chloride level ( $>60 \mathrm{mmol} / \mathrm{L}$ ), a diagnostic criteria for confirmation of CF [2].

Review of our database revealed 8 patients who had the unique combination of PBS as the first manifestation, but nondiagnostic sweat chloride levels (range 24-57 mmol/L). All presented before $7 \mathrm{mo}$ of age and majority (88\%) in the first summer. Documented mean $\mathrm{pH}$, serum bicarbonate, sodium and potassium values were 7.61 (Normal: 7.35-7.45), $37.3 \mathrm{mmol} / \mathrm{L}(22-29 \mathrm{mmol} / \mathrm{L}), 121.8 \mathrm{mmol} / \mathrm{L}(135-$ $145 \mathrm{mmol} / \mathrm{L})$ and $2.8 \mathrm{mmol} / \mathrm{L}(3.5-5 \mathrm{mmol} / \mathrm{L})$, respectively and were corrected easily within $72 \mathrm{~h}$. Final diagnosis of CF was confirmed either by repeated sweat chloride tests $(\mathrm{N}=5)$ or by CFTR mutation analysis $(\mathrm{N}=3)$. Children in this group had milder phenotype at symptom onset. Two patients had isolated PBS at onset, respiratory involvement manifested only after the first year in 50\% and half of them are pancreatic sufficient. Despite the subtle features in infancy, by end of first decade, there was bronchiectasis in three and one child died due to respiratory failure.

PBS during summer or intercurrent illness should alert the pediatrician to the possibility of CF. Close follow-up and repeated sweat testing is indicated even if PBS is an isolated feature and sweat chloride values are nonconfirmatory. High index of suspicion is necessary to make CF diagnosis in infancy. Apparent mild phenotype might contribute to delayed diagnosis, suboptimal therapy, and poor outcome in some.

\section{Declarations}

Conflict of Interest None.

\section{References}

1. Mantoo MR, Kabra M, Kabra SK. Cystic fibrosis presenting as pseudo-bartter syndrome: an important diagnosis that is missed! Indian J Pediatr. 2020;87(9):726-32.

2. Farrell PM, White TB, Ren CL, et al. Diagnosis of cystic fibrosis: consensus guidelines from the cystic fibrosis foundation. J Pediatr. 2017;181:S4-15.e1.

Publisher's Note Springer Nature remains neutral with regard to jurisdictional claims in published maps and institutional affiliations.

Sneha Deena Varkki

cfcare@cmcvellore.ac.in

1 Department of Pediatrics, Christian Medical College, Vellore 632004, Tamil Nadu, India 